\title{
Book review: Transport for suburbia: Beyond the automobile age, by Paul Mees
}

\author{
Jessica E. Schoner \\ University of Minnesota ${ }^{\text {a }}$
}

\section{Transport for suburbia: Beyond the automobile age}

Paul Mees

Earthscan Publishing, 2010

ISBN: 978-1-84407-740-3

"The cause of sustainable transport needs to be detached from the crusade against suburbia." (Mees 2010, p. 200)

Abstract: This book review summarizes and evaluates Transport for Suburbia: Beyond the Automobile Age, by Paul Mees. The argument in Transport for Suburbia is that density is not a necessary prerequisite for an effective transit system, and that transfers can be used as a tool to expand the scope of a transit network. Mees presents this argument and his suggestions for improving transit service through a series of narratives about car culture, land use, and best and worst case transit system scenarios.

In Transport for Suburbia, Mees attempts to demonstrate that despite the current discourse in public transport, density is not a prerequisite for achieving a high public transit mode share. He argues this point through historic narrative on public transit around the world, akin to Robert Cervero's The Transit Metropolis, comparing density factors, built environment and land use patterns, and transit network structures across regions. Mees starts by debunking many common myths about the fall of public transit and rise of automobile culture. Anyone who clings to the narrative of GM conspiring to abolish streetcar transit or to the belief that Los Angeles is the capital of low-density sprawl will be challenged in Chapter 2. The "need" for high density corridors to make transit service efficient, Mees argues, is a red herring distracting us from the potential to implement effective transit service now to serve the lower density suburban built environment that has evolved over the last century: "Most of the houses New Yorkers or Melbournians will inhabit in 2050 already exist." (p. 53) Instead, Mees turns to economic structure and the strength of a region's urban core to explain transit use. In US and Canadian cities, the share of economic activity occurring in the Central Business District (CBD), it turns out, correlates much more strongly with transit mode share than regional density (p. 65). He concludes that compact city development is not a panacea, and the right urban structure can support high-quality public

aschon082@umn.edu transport networks with much lower urban densities than previously thought possible.

The text convincingly documents case after case of public transit privatization gone wrong, leading to the conclusion that a single public agency must be tasked with operating an integrated, multi-modal public transit network in a natural monopoly. While systems today often seek out economies of scale on highly-used transit corridors, Mees argues that it is the economies of service integration and scope that produce functional, sustainable transit networks. The concept of networks arises again and again throughout the book. Mees argues that transfers, when planned for and accompanied by excellent transfer facilities and low headways, are an opportunity to service a wider range of origin-destination pairs. A random transfer network of very simple, high frequency bus and/or rail routes provides the flexibility of car travel at almost any time of day or night with minimal planning hassle. Popular routes cross-subsidize the ones with lower ridership, but the low-volume routes are essential for providing the volumes necessary on trunk lines to generate sufficient fare revenue. These interdependencies are the critical piece missing from less successful transit systems in the US and Australia today; as long as routes are planned to minimize transfers, routes will be long and frustrating, focused on serving a small number of passengers who live, work, and play along the route, and the transfers themselves will continue to be unpleasant, long, and unpredictable. 
Transport for Suburbia's format is equally accessible to the casual reader and the urban planner or policymaker. The evidence presented is in the form of well-documented historical narrative and simple descriptive statistics. Mees selects cases that simultaneously challenge assumptions; such as the GM streetcar conspiracy, and give the reader hope for a brighter transit future, like rural towns in the Canton of Zurich that despite their size are surprisingly well serviced by transit.

While Mees does present his proposed solutions for public transit, these tactics do not seem easily implemented or politically or financially feasible. He concedes that the successful systems are as much a product of functional organizational history and the political will to treat transit as a serious form of transportation, not just a social service for those too old, too young, or too poor to drive. While these points do not contradict his thesis that density is not a strictly essential component for successful transit, they are substantial barriers to implementing his proposed changes. Mees tips his hat to some of the government fragmentation and entrenched habits we deal with in auto-dominated cities, but fails to offer solutions that would make his exciting network proposals more implementable. He also spends very little time discussing the actual costs of these systems, instead relying on the idea that it is possible to get ridership levels that reduce or eliminate subsidies, so designing for increased ridership should be the goal.

Overall, Transport for Suburbia is an interesting read for anyone tired of the narrative of 'density, density, density' in order to make transit work. The book cannot solve every city's transit woes; indeed Mees' solutions may be completely impossible to implement in most cities, but the discussion provokes serious questions about the current research on necessary density levels and the role of transfers in a transit network. 